\title{
Placental thrombomodulin expression in recurrent miscarriage
}

\author{
Piergiorgio Stortoni ${ }^{1}$, Monia Cecati ${ }^{2}$, Stefano R Giannubilo ${ }^{1 *}$, Davide Sartini ${ }^{2}$, Angelo Turi ${ }^{1}$, Monica Emanuelli ${ }^{2}$, \\ Andrea L Tranquilli ${ }^{1}$
}

\begin{abstract}
Background: Early pregnancy loss can be associated with trophoblast insufficiency and coagulation defects. Thrombomodulin is an endothelial-associated anticoagulant protein involved in the control of hemostasis and inflammation at the vascular beds and it's also a cofactor of the protein C anticoagulant pathway.

Discussion: We evaluate the Thrombomodulin expression in placental tissue from spontaneous recurrent miscarriage and voluntary abortion as controls. Thrombomodulin mRNA was determined using real-time quantitative polymerase chain reaction. Reduced expression levels of thrombomodulin were found in recurrent miscarriage group compared to controls (1.82-fold of reduction), that corresponds to a reduction of 45\% (from control group Delta $(T)$ of thrombomodulin expression in spontaneous miscarriage group respect the control groups.
\end{abstract}

Summary: We cannot state at present the exact meaning of a reduced expression of Thrombomodulin in placental tissue. Further studies are needed to elucidate the biological pathway of this important factor in the physiopathology of the trophoblast and in reproductive biology.

\section{Background}

Thrombomodulin (TM) is a glycoprotein receptor composed of 559 amino acid residues and expressed mainly on the endothelial surface of blood vessels and in the placental syncytiotrophoblast [1]. It is composed of different structural domains: an N-terminal lectinlike module, a hydrophobic region, six EGF-like repeats, a Ser/Thr-rich region, a trans-membrane region and a short cytoplasmic tail [2]. This glycosylated transmembrane receptor for activated coagulation Factor IIa [3] in the intact endothelium thrombomodulin forms a complex with thrombin which is responsible of converting protein $\mathrm{C}$ to activated protein $\mathrm{C}$ $[1,4,5]$. The Thrombomodulin-thrombin complex balances the substrate specificity of thrombin, erasing its procoagulant properties, and improving the conversion of protein $\mathrm{C}$ into its activated form [6]. Protein $\mathrm{S}$ and activated protein $C$ cleave in a proteolytic way the activated coagulation factors Va and VIIIa: all this complex process inactivates the enzymatic complexes that

\footnotetext{
* Correspondence: s.giannubilo@univpm.it

'Department of Clinical Sciences, Polytechnic University of Marche, Ancona, Italy
}

C 2010 Stortoni et al; licensee BioMed Central Ltd. This is an Open Access article distributed under the terms of the Creative Commons Attribution License (http://creativecommons.org/licenses/by/2.0), which permits unrestricted use, distribution, and reproduction in any medium, provided the original work is properly cited. make coagulation factors $\mathrm{Xa}$ and thrombin active. If the blood coagulation inhibitor Thrombomodulin lacks from trophoblast cells of the mouse placenta, a fatal arrest of placental morphogenesis occurs [7], leading to embryo failure probably due to tissue factorinitiated activation of the blood coagulation cascade at the fetus-maternal interface [8]. In addition, TM integrates fibrinolytic and anti-inflammatory responses also independently by protein $\mathrm{C}$ and thrombin. The analysis of different mouse models has revealed novel and in part organ-specific functions of TM, most notably in the vascular bed of the placenta. In these mouse models, the severity and phenotypic expression of thrombosis is highly variable and is dependent on the interaction with secondary genetic or environmental modifiers. The mutant mouse strains replicate important aspects of thrombophilia and thrombosis in humans [9].

The functions of TM are exerted in two distinct tissues: in non-endothelial extra-embryonic tissues, required for proper function of the early placenta, in embryonic blood vessel endothelium whose absence causes lethal consumptive coagulopathy [10].
C Biomed Central 


\section{Discussion}

With this background, we performed a prospective casecontrol study measuring the gene expression of thrombomodulin in placental tissues from spontaneous recurrent miscarriage and voluntary abortion by Real-Time quantitative PCR to elucidate the role of this factor on human miscarriage.

Trophoblastic tissue was obtained during surgical uterine evacuation in 11 women with recurrent miscarriage and 20 healthy primiparous pregnant women undergoing elective termination of pregnancy matched for gestational age. Recurrent miscarriage was defined as occurrence of three consecutive spontaneous miscarriages before 20 weeks' gestation [11]. In the group with recurrent miscarriage were recruited only the patients with incoming miscarriage ( $<12$ hours) who were admitted in hospital for threatened abortion.

All women enrolled were regularly menstruating, with a cycle length of $<35$ days. Clinical details were recorded for each woman, and only patients who were certain of their menstrual dates entered the study group. Specific exclusion criteria for all women enrolled included conception by assisted reproduction, gestational diabetes, diabetes mellitus, a history of smoking and hypertension, proteinuria, renal, cardiovascular hepatic, and endocrine disease, metabolic disorders, and current infection or history of all types of infection. Moreover, according to our internal protocol, enrolled subjects did not present with thyroid disease, congenital or acquired thrombophilic disorders, or chromosomal or other fetal and uterine anomalies.

None of these women had non-obstetric clinical features of antiphospholipid syndrome (i.e., history of thrombosis, autoimmune thrombocytopenia, systemic lupus erythematosus, or other autoimmune conditions). All had negative test results for lupus anticoagulant and fewer than 20 IgG phospholipid-binding units of anticardiolipin antibodies. Furthermore, none of the recruited women took any regular medication, which included antihypertensive drugs or $\mathrm{MgSO} 4$, before and during the experiment, and none of the control subjects were on oral contraception; only folic acid $(400 \mu \mathrm{g} /$ day $)$ was taken during pregnancy and diets were comparable for all groups.

Since in first trimester placenta a number of other cell types present within the villous stroma such as fibroblasts, myofibroblasts, smooth muscle cells, pericytes and endothelial cells as well as maternal and fetal blood cells are potential contaminants, the tissues derived by curettage were characterized using antibodies to cytokeratin antibodies specific for the isoform 7 to obtain an high grade of trophoblast purification [12].

All specimens were snap-frozen in liquid nitrogen and stored at $-80^{\circ} \mathrm{C}$ until use. The total length of processing time was less than 10 minutes. The study was performed in accordance with the principles of the Declaration of Helsinki as revised in 2001. The study was approved by the local ethics committee, and informed consent was given by all women enrolled in the study. A piece of the frozen tissue (20-40 mg) was homogenized in lysis buffer, and the total RNA was extracted with an RNA isolation kit (Promega, Madison, WI). RNA samples were tested by ultraviolet absorption at $260 \mathrm{~nm}$ in order to determine RNA concentration. The quality and concentration of the RNA samples were further confirmed by electrophoresis on denaturated $1 \%$ agarose gels. Two micrograms of RNA were reverse transcribed in a total volume of $25 \mu \mathrm{l}$ for $60 \mathrm{~min}$ at $37^{\circ}$ $C$ with M-MLV Reverse Transcriptase (Promega, Madison, WI) using random nonamers in order to obtain complementary DNA (cDNA). cDNA was used for realtime quantitative PCR. To avoid false-positive results attributable to the amplification of contaminating genomic DNA in the cDNA preparation, the primers were selected to flank an intron and PCR efficiencies were tested and found to be close to 1 . The following primers were used: 5'CTCTTCCAGCCTTCCTTCCT-3' (forward), 5'-AGCACTGTGTTGGCGTACAG-3' (reverse) for $\beta$-actin, and 5'-TAACGAAGACACAGACTGCGATT-3' (forward) and 5'-ACCTTGACCTCGTGGGCTAG 3' (reverse) for thrombomodulin. The genes were run in duplicate using SYBR Green chemistry. All samples, taken from each pregnancy, were tested in triplicate using as reference gene $\beta$-actin for data normalization to correct for variations in RNA quality and quantity. To increase accuracy of normalization, a second housekeeping gene (GAPDH) was used. No significant differences were observed in thrombomodulin expression levels with the use of the additional endogenous control. Direct detection of the PCR products was monitored by measuring the fluorescence produced by SYBR Green I dye binding to the double-strand DNA after every cycle. These measurements were then plotted against cycle numbers. The parameter $C t$ (threshold cycle) was defined as the cycle number at which the first detectable fluorescence signal above the threshold was observed. The real-time PCR products were also electrophoresed on $2 \%$ agarose gel, and the intensity of amplicons of expected size was evaluated (Figure 1). Fold changes in relative gene expression were calculated by $2^{-\Delta(\Delta C t)}$ where $\Delta C t=C t$ (thrombomodulin) - Ct $(\beta-$ actin) and $\Delta(\Delta C t)=$ mean $\Delta C t$ (pathological placentas) mean $\Delta C t$ (normal placentas). The Mann-Whitney $\mathrm{U}$ test was performed to compare data from control and pathological placentas. Differences were considered significant at $\mathrm{p}<0.05$. The results were obtained as "fold changes" in relative gene expression of study group 

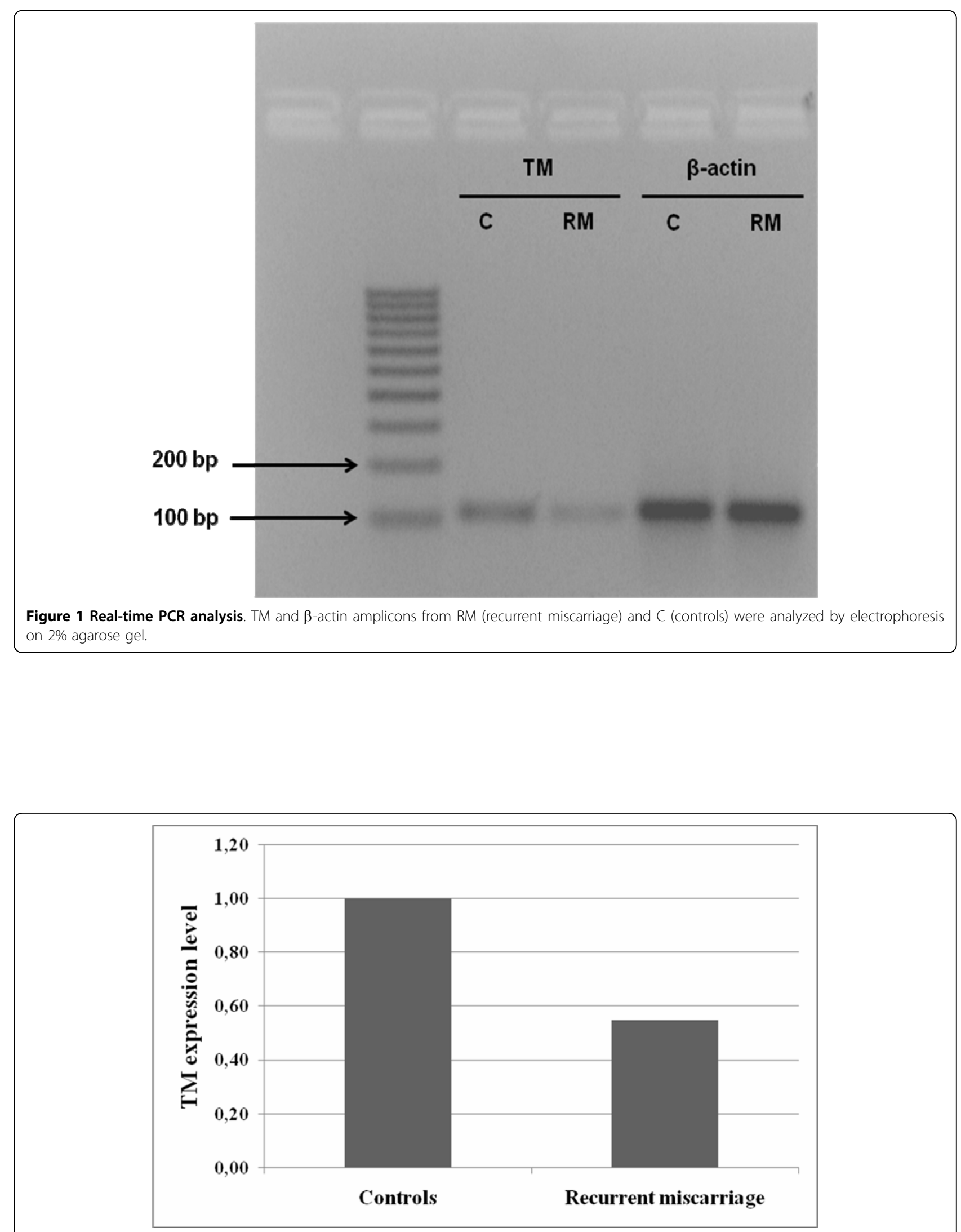

Figure 2 Thrombomodulin expression is significantly reduced in spontaneous recurrent miscarriage versus control group ( $p<0.05$ ). 
respect to controls. All values were expressed as Mean $\Delta \mathrm{Ct} \pm$ Standard Deviation, Median $\Delta \mathrm{Ct}$ and first and third Quartile. The two groups were comparable for maternal age and gestational age, the characteristics of the patients recruited are reported in the Table 1. Reduced expression levels of thrombomodulin were found in recurrent miscarriage group compared to controls (1,82-fold reduction), that corresponds to a reduction of $45 \%$ (from control group $\Delta \mathrm{Ct}$ ) of thrombomodulin expression in spontaneous miscarriage group respect the control group (Figure 2).

Thrombomodulin is considered a protein involved in coagulation, cancer and embryogenesis. The altered coagulation process leads to a precocious placental failure, but some studies underline that Thrombomodulin has an anti-inflammatory ability through both protein $\mathrm{C}$ dependent and independent pathways. The activation of the coagulation cascade may result in a positive-feedback loop consisting of thrombin-mediated repression of Thrombomodulin-dependent protein $C$ activation [13]: this aspect shows the strict relation between coagulation and inflammation, two processes that enhance one to each other leading to the early placental vascular damage. In pregnancy, fibrinolysis is controlled by the maternal endothelium and placenta, both of which are central to the pathogenesis of some obstetric pathologies [14]. Some works have discussed that plasma Thrombomodulin levels might point out placental vascular endothelial damage reflecting on birthweight [15]. On the contrary, other studies have focused the attention on the role of the Thrombomodulin in cell invasivity and capability to perform intravasation and extravasation, during local invasion.

In this work we found a reduced expression of Thrombomodulin in placental tissue of women who experienced spontaneous recurrent abortion by RealTime quantitative PCR.

This result confirms the observations that loss of function of Thrombomodulin causes early post-implantation embryonic lethality [16], underlying that

Table 1 Gestational age and Thrombomodulin (TM) expression level in the two groups

\begin{tabular}{llll}
\hline & $\begin{array}{l}\text { Controls } \\
(\mathbf{N}=\mathbf{2 0})\end{array}$ & $\begin{array}{l}\text { Recurrent } \\
\text { Miscarriage } \\
\mathbf{( N = 1 1 )}\end{array}$ & $\mathbf{p}<$ \\
\hline Age (yrs) & $32.6 \pm 2.1$ & $33.2 \pm 2.9$ & N.S. \\
$\begin{array}{l}\text { Gestational Age } \\
\text { (weeks) }\end{array}$ & $10.1 \pm 1.91$ & $10.9 \pm 1.56$ & N.S. \\
TM $\Delta$ Ct (Median) 6.410 & 7.133 & $<0.05$ \\
TM $\Delta$ Ct (Mean $\pm 6.377 \pm 0.213$ & $7.230 \pm 0.870$ & $<0.05$ \\
SD) & & 6,77 & $<0.05$ \\
First quartile & 6,14 & 7.95 & $<0.05$ \\
Third quartile & 6.59 & &
\end{tabular}

Thrombomodulin expression in non-endothelial placental cells is required for a normal function of the early placenta. By this hypothesis the absence of Thrombomodulin from blood vessel endothelium may cause excessive activation of the embryonic blood coagulation system [17]. We cannot state at present the exact meaning of a reduced expression of Thrombomodulin in placental tissue. Further studies are needed to elucidate the biological pathway of this important factor in the physiopathology of the trophoblast and in reproductive biology.

\section{Author details}

'Department of Clinical Sciences, Polytechnic University of Marche, Ancona, Italy. ${ }^{2}$ Department of Biochemistry Biology and Genetics, Polytechnic University of Marche, Ancona, Italy.

\section{Authors' contributions}

PS, SRG, ME, AT and ALT conceived of the study, and participated in its design and coordination and helped to draft the manuscript, MC carried out the molecular genetic studies, participated in the sequence alignment and drafted the manuscript. All authors read and approved the final manuscript.

\section{Competing interests}

The authors declare that they have no competing interests.

Received: 14 October 2009

Accepted: 5 January 2010 Published: 5 January 2010

\section{References}

1. Maruyama I, Elliott Bell C, Majerus PW: Thrombomodulin is found on endothelium of arteries, veins, capillaries, and lymphatics, and on syncytiotrophoblast of human placenta. J Cell Biol 1985, 101:363-371.

2. Dittman WA, Majerus PW: Structure and function of thrombomodulin: a natural anticoagulant. Blood 1990, 75:329-336.

3. Esmon CT: Regulation of blood coagulation. Biochim Biophys Acta 2000, 1477:349-360.

4. Wouwer Van de M, Collen D, Conway EM: Thrombomodulin protein CEPCR system:integrated to regulate coagulation and inflammation. Arterioscler Thromb Vasc Biol 2004, 24:1374-1383.

5. Dahlbäck B, Villoutreix BO: The anticoagulant protein C pathway. FEBS 2005, 579:3310-3316.

6. Fuentes-Prior $P$, Iwanaga $Y$, Huber $R$, Pagila $R$, Rumennik $G$, Seto $M$, Morser J, Light DR, Bode W: Structural basis for the anticoagulant activity of the thrombinthrombomodulin complex. Nature 2000, 404:518-525.

7. Sood R, Sholl L, Isermann B, Zogg M, Coughlin SR, Weiler H: Maternal Par4 and platelets contribute to defective placenta formation in mouse embryos lacking thrombomodulin. Blood 2008, 112:585-591.

8. Isermann B, Sood R, Pawlinski R, Zogg M, Kalloway S, Degen JL, Mackman N, Weiler $\mathrm{H}$ : The thrombomodulin-protein $\mathrm{C}$ system is essential for the maintenance of pregnancy. Nat Med 2003, 9:331-337.

9. Weiler H: Mouse models of thrombosis: thrombomodulin. Thromb Haemost 2004, 92:467-477.

10. Bicheng N, Hui Y, Shaoyu Y, Peter LH, Lumsden AB, Qizhi Y, Changyi C: Creactive protein decreases expression of thrombomodulin and endothelial protein C receptor in human endothelial cells. Surgery 2005 , 138:212-222.

11. Tuckerman E, Laird SM, Stewart R, Wells M, Li TC: Markers of endometrial function in women with unexplained recurrent pregnancy loss: a comparison between morphologically normal and retarded endometrium. Hum Reprod 2004, 19:196-205.

12. Blaschitz A, Weiss U, Dohr G, Desoye G: Antibody reaction patterns in first trimester placenta: Implications for trophoblast isolation and purity screening. Placenta 2000, 21:733-741.

13. Kaare M, Ulander VM, Painter JN, Ahvenainen T, Kaaja R, Aittomäki K: Variations in the thrombomodulin and endothelial protein $C$ receptor 
genes in couples with recurrent miscarriage. Hum Reprod 2007, 22:864-

868.

14. Hunt BJ, Missfelder-Lobos H, Parra-Cordero M, Fletcher O, Parmar K,

Lefkou E, Lees CC: Pregnancy outcome and fibrinolytic, endothelial

markers and coagulation markers in women undergoing uterine artery Doppler screening at 23 weeks. J Thromb Haemost .

15. Varol FG, Ozgen L, Sayin C, Demir M: Correlation Between Maternal Plasma Thrombomodulin and Infant Birth Weight in Hypertensive Disorders of Pregnancy. Clin Appl Thromb Hemost 2009, 15:166-170.

16. Isermann B, Hendrickson SB, Hutley K, Wing M, Weiler H: Tissue restricted expression of thrombomodulin in the placenta rescues thrombomodulin deficient mice from early lethality and reveals a secondary developmental block. Development 2001, 28:827-838.

17. Ford VA, Wilkinson JE, Kennel SJ: Thrombomodulin distribution during murine development. Roux's Archiv Dev Biol 1993, 202:364-370.

doi:10.1186/1477-7827-8-1

Cite this article as: Stortoni et al:: Placental thrombomodulin expression

in recurrent miscarriage. Reproductive Biology and Endocrinology 2010 8:1.

Publish with Biomed Central and every scientist can read your work free of charge

"BioMed Central will be the most significant development for disseminating the results of biomedical research in our lifetime. "

Sir Paul Nurse, Cancer Research UK

Your research papers will be:

- available free of charge to the entire biomedical community

- peer reviewed and published immediately upon acceptance

- cited in PubMed and archived on PubMed Central

- yours - you keep the copyright 